15.P28

\title{
Fetal Dopaminergic Cell Suspension Grafts to Striatum in Aged Rats with Motor Disabilities
}

\author{
C.I. Fernandez, K. de la Cuétera, O. Castellanos, J.C. García, R. Macias, L. Francis and A. Valle \\ Centro Iberolatinoamericano de Transplante y Regeneración del Sistema Nervioso. \\ Ave 25 \# 15805 Playa, C. Habana, Cuba
}

Aged rodents, like aged humans, exhibit a decline in sensory and motor functions, learning and memory $/ 1 /$. The altered dopaminergic transmission in the nigrostriatal system is implicated in movement disorders and sensorimotor coordination disabilities associated with aging $12 /$.

Three male Sprague-Dawley rat groups were used: young controls ( $4-5$ months old, $n=15$ ); aged rats $(24-26$ months old, $n=15)$ that received nigral grafts, and age-matched controls (24-26 months old, $n=15)$ without grafts.

Motor coordination skills were assessed on a modified Wallace et al. battery $/ 3 /$ using narrow bridge tasks (square and round cross section) and wire suspension, to evaluate latency to fall and fall number when the rat is placed over the bridge. The Marshall scale of vigor and success /4/ was used to assess swimming performance. The rating scale was from zero (poorest) to 3 (best). Fetal cell suspensions (CRL 10-14 mm) were bilaterally and stereotaxically injected into two different sites in the neostriatum. Each site graft consisted of two deposits $(86,000 \mathrm{cells} / \mu \mathrm{l})$ injected at different levels (1.5-2 $\mathrm{mm}$ above each other). Behavioral testing was conducted on all rats before and 12 weeks after transplantation. The brains from 5 animals of each age group were processed for tyrosine hydroxylase immunohistochemistry, and the same number was used to measure striatal dopamine level and its metabolites (HVA and DOPAC) by the HPLC-ECD method /5/.

Surviving grafts were found in both sides of the brain, containing $\mathrm{TH}$ positive fibers and soma, and exhibiting an adequate host-donor integration, similar to that obtained by Gage et al. 16/. Before grafting, all aged rats were significantly impaired with respect to young controls.
During the second evaluation the grafted group exhibited a significant improvement in narrow bridge performance parameters. An increased latency and a decreased fall number were found when these rats were compared with aged nongrafted or aged matched controls. Swimming abilities in transplanted rats showed remarkable improvement. The rats continued swimming for longer, using all limbs more vigorously with the head mostly above the water surface. Relative to aged controls, old grafted animals had a significant increase in striatal dopamine levels, but its metabolites (HVA and DOPAC) showed a slight reduction. Other authors have reported that dopamine concentrations decline in old rodents 17/, but the biochemistry of the aged grafted striatum has not yet been clearly defined.

The above results demonstrate that during aging changes in dopaminergic system function can be related to age-impaired motor functions. Thus, neural grafting in aged rodents provides a model to evaluate the potential aged brain plasticity and the possible responsiveness to treatment in aged brain with age-associated motor disorders.

\section{REFERENCES}

1. Ciocon MD, Potter JF. Geriatrics 1988 ; 43: 43-48.

2. Godefroy $F$ et al. J Neural Transm 1991; 83: 13-24.

3. Wallace JE et al. J Gerontol 1980; 35: 355-363.

4. Marshall JF, Barrios N. Science 1979; 206: 477-479.

5. Perry TL et al. Life Sci 1985; 36: 1233-1238.

6. Gage FH et al. Ann NY Acad Sci 1988; 515: 383-394.

7. Morgan DG et al. Ann NY Acad Sci 1988; 515: 144-190. 

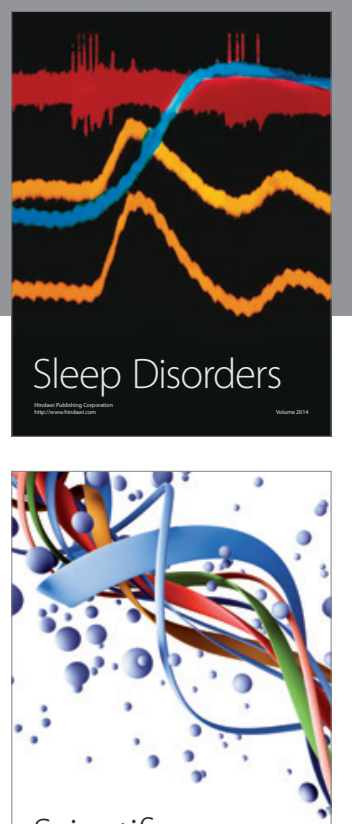

Scientifica
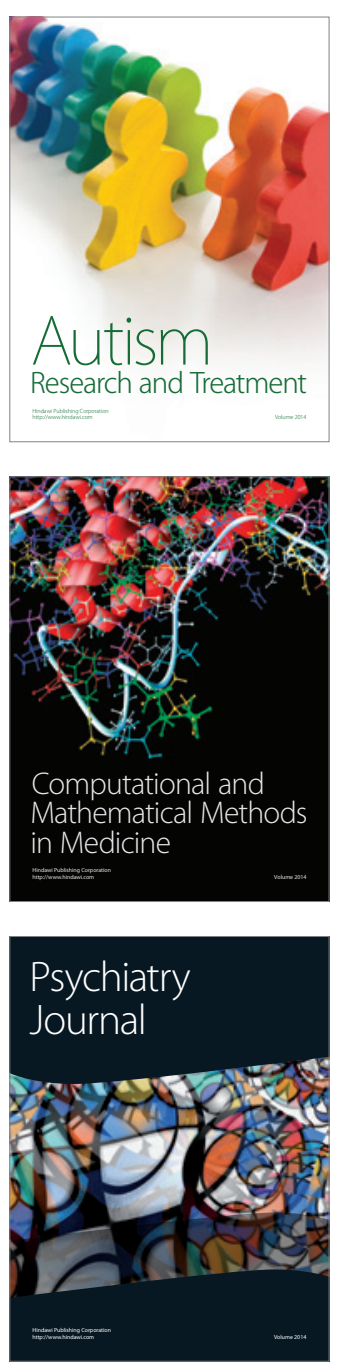
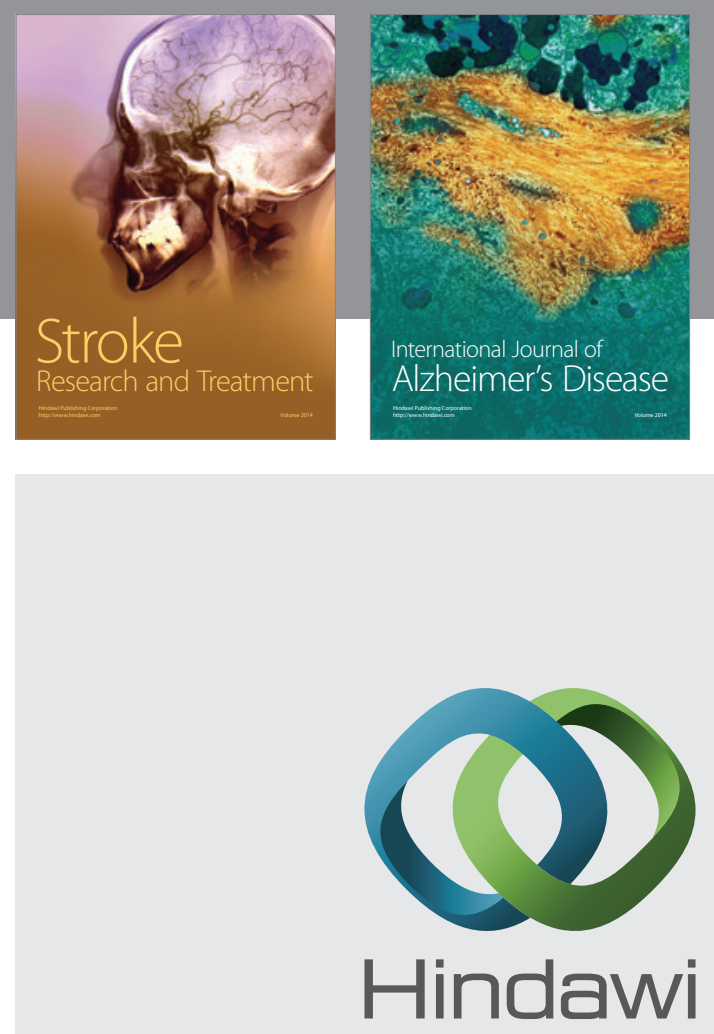

Submit your manuscripts at

http://www.hindawi.com
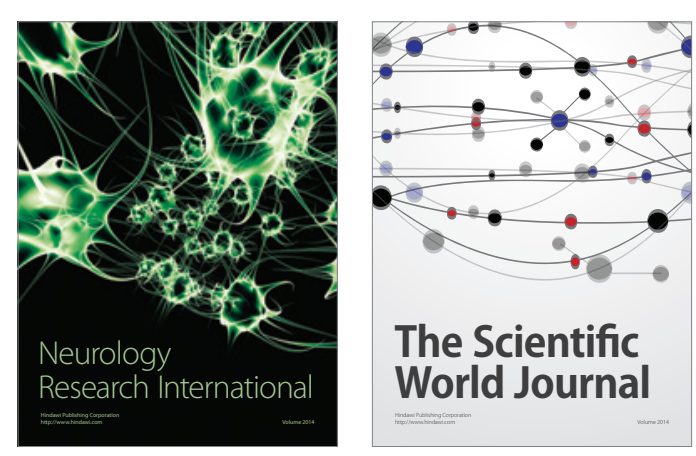

The Scientific World Journal

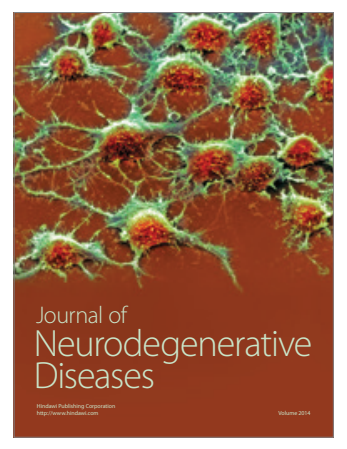

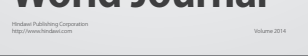

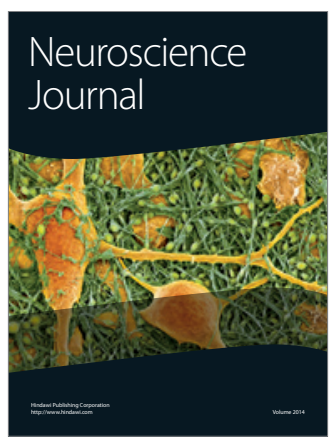

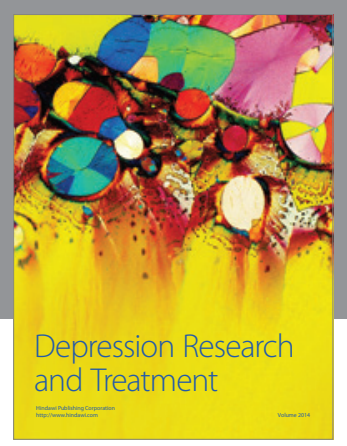
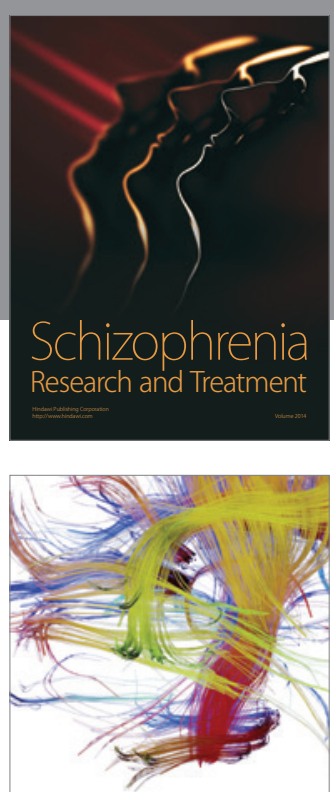

Brain Science

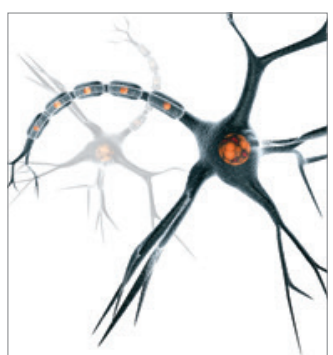

Neural Plasticity
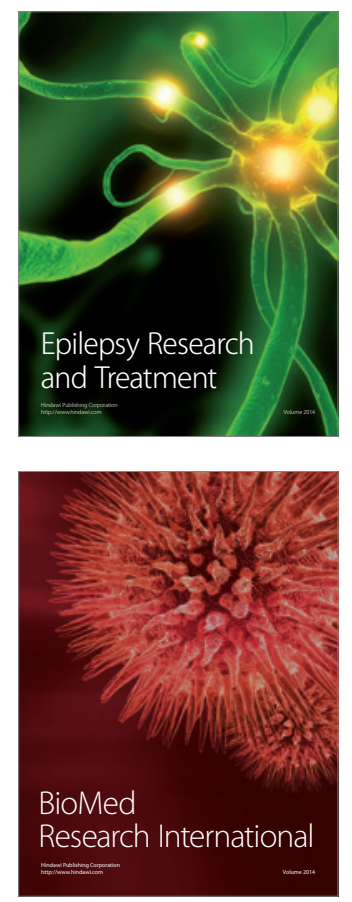

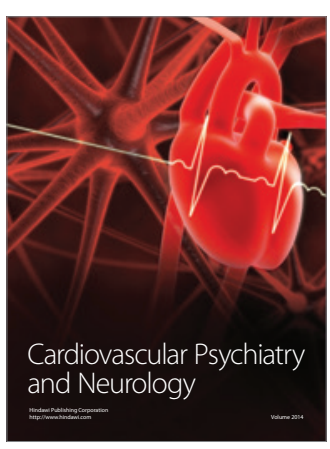

Parkinson's

Disease
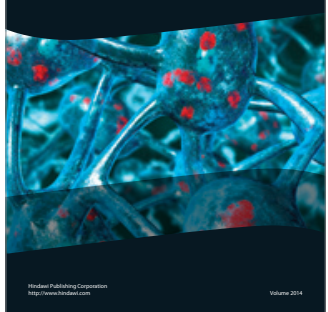